\begin{tabular}{|c|c|c|c|c|}
\hline Share: Social Work Jurnal & VOLUME: 10 & NOMOR: 2 & HALAMAN: $239-250$ & $\begin{array}{r}\text { ISSN: 2339-0042 (p) } \\
\text { ISSN: 2528-1577 (e) } \\
\text { DOI: 10.24198/share.v10i2.31131 }\end{array}$ \\
\hline
\end{tabular}

\title{
KEMISKINAN SOSIAL DI WAPEKO : Analisa Kapital Sosial (Studi Kasus Kampung Wapeko, Distrik Kurik, Kabupaten Merauke - Papua)
}

\author{
Rendra Permana ${ }^{1}$, Robert M.Z. Lawang' \\ 1,2Medco Foundation \\ reigamana@gmail.com
}

\begin{abstract}
ABSTRAK
Memahami bentuk kapital sosial dalam masyarakat heterogen dapat membantu mendukung pembangunan sosial yang bermuara kepada pengentasan kemiskinan. Konsep kemiskinan sosial dari Lewandowsky digunakan sebagai alat analisis kemiskinan yang dihadapi orang Marind. Penelitian ini berfokus pada masalah kemiskinan dan kapital sosial di Kampung Wapeko, distrik Kurik, Kabupaten Merauke, Papua. Tujuan dari penelitian adalah mendeskripsikan dan menganalisis gambaran bentuk kapital sosial masyarakat orang asli Papua (Marind) dan transmigran di kampung Wapeko serta fungsi kapital sosial yang terbentuk dari kedua masyarakat tersebut dalam pengentasan kemiskinan di kampung Wapeko. Metode penelitian yang digunakan adalah penelitian kualitatif dengan pendekatan deskriptif. Dari hasil penelitian, diketahui profesi orang Marind sebagai subsisten (pemburu, peramu), belum mengolah sumber daya alam karena tidak adanya kemampuan teknis dan jaringan dalam pengelolaannya (bertani, berdagang). Orang Marind hanya mampu memiliki kebutuhan dasar (rumah, listrik, air bersih) serta akses ekonomi yang sangat terbatas. Kapital sosial warga Marind berupa bonding social capital dengan penekanan pada norma pembagian dan pengelolaan lahan, kekerabatan (marga), pemanfaatan hutan serta konservasi tradisional (sasi). Tipologi bonding social capital orang Marind menimbulkan kesulitan untuk dapat menghadapi perubahan kondisi kampung dari bentuk kehidupan tradisional menuju modern karena kapital sosial yang dimiliki tidak mampu menggapai secara maksimal kapital sosial dari kelompok lain yang lebih permisif. Warga transmigran di Wapeko memiliki bridging social capital dengan norma kerjasama (gotong royong) dan etos kerja pantang menyerah yang menimbulkan jaringan yang kuat dalam menjalankan beragam variasi mata pencaharian (bertani, berdagang, pegawai) sehingga kondisi ekonominya meningkat. Pelaksanaan norma warga transmigran menimbulkan kepercayaan dari orang Marind dalam hal pemberian akses pembagian dan pengelolaan lahan serta pemanfaatan hutan. Hal tersebut memicu munculnya bridging social capital diantara dua kelompok tersebut dengan penguatan pada munculnya norma sewa lahan dan perdagangan hasil hutan (pengepul) sehingga menimbulkan pergerakan kesejahteraan ekonomi di kedua pihak. Kesimpulan penelitian adalah kemiskinan yang terjadi pada orang Wapeko disebabkan karena tidak dimilikinya bridging social capital.
\end{abstract}

Kata Kunci : Kapital Sosial Vertikal, Kemiskinan Sosial, Livelihood, Pembangunan. 


\begin{tabular}{|c|c|c|c|c|}
\hline Share: Social Work Jurnal & VOLUME: 10 & NOMOR: 2 & HALAMAN: $239-250$ & $\begin{array}{r}\text { ISSN: 2339-0042 (p) } \\
\text { ISSN: 2528-1577 (e) } \\
\text { DOI: 10.24198/share.v10i2.31131 }\end{array}$ \\
\hline
\end{tabular}

\section{ABSTRACT}

Understanding the form of social capital in heterogeneous societies can help support social development that leads to poverty alleviation. Lewandowsky's concept of social poverty is used as a tool for analyzing the poverty faced by Marind people. This research focuses on the problems of poverty and social capital in Wapeko village, Kurik District, Merauke Regency, Papua. The purpose of this research is to describe and analyze the description of the social capital forms of indigenous Papuans (Marind) and transmigrants in Wapeko village and the function of social capital formed by the two communities in poverty alleviation in Wapeko village. The research method used is qualitative research with a descriptive approach. From the research results, it is known that the Marind profession as subsistence (hunters, gatherers), have not processed natural resources due to the absence of technical and network capabilities in their management (farming, trading). The Marind people are only able to have basic needs (housing, electricity, clean water) and very limited economic access. The social capital of Marind residents is in the form of bonding social capital with an emphasis on the norms of land division and management, kinship (marga), forest use and traditional conservation (sasi). The typology of social bonding capital of the Marind people creates difficulties in being able to deal with changes in village conditions from traditional to modern forms of life because their social capital is not able to maximize social capital from other, more permissive groups. Transmigrants people in Wapeko have bridging social capital with the norm of cooperation (gotong royong) and an unyielding work ethic which creates a strong network in carrying out various variations in their livelihoods (farming, trading, employees) so that their economic conditions improve. The implementation of the norms of transmigrants people has generated trust from the Marind people in granting access to land distribution and management as well as forest use. This has triggered the emergence of bridging social capital between the two groups by strengthening the emergence of land lease norms and trade in forest products (pengepul), causing a movement of economic welfare on both sides. The conclusion of this research is that poverty that occurs in Wapeko people is due to their lack of bridging social capital.

Keywords: Vertical Social Capital, Social Poverty, Livelihood, Development.

\section{PENDAHULUAN}

Kemiskinan sosial sangat berkaitan erat dengan keberadaan kapital sosial, seperti yang dinyatakan oleh Lewandowsky: "social poverty is an absence or dearth of vertical capital. It is a lack or scarcity of the kinds of social trust and connections that link individuals and groups in ways that foster mobility, associations, and shared cooperative actions up and down the socioeconomic and cultural ladder" (Lewandowsky 2008, p.28, dikutip dalam Social Poverty in two extreme cases in Manggarai - East Nusa Tenggara Province, Robert M.Z. Lawang, 2018). Paparan Lewandowsky tersebut menekankan kemiskinan sosial adalah ketiadaan dan kelangkaan modal sosial vertikal dimana yang dimaksudkan adalah kurang atau langkanya kepercayaan sosial dan koneksi yang menghubungkan individu dan kelompok dalam rangka mendorong mobilitas, asosiasi maupun berbagi aksi dukungan dalam turun naiknya tangga sosial ekonomi serta kultural.

Menelisik proses pembangunan sosial untuk mengentaskan kemiskinan tentunya juga harus memperhatikan keberadaan kapital sosial dari masyarakat dimana proses tersebut dijalankan. Hal tersebut bermuara kepada pemahaman kapital sosial (social capital) yang dijabarkan sebagai kemampuan masyarakat untuk bekerja bersama, demi mencapai tujuan bersama, di dalam berbagai kelompok dan organisasi (Coleman, 1999). Dilihat dari Tipologinya, kapital sosial terdiri dari kapital sosial terikat (bonding) dan kapital sosial 


\begin{tabular}{|c|c|c|c|c|}
\hline Share: Social Work Jurnal & VOLUME: 10 & NOMOR: 2 & HALAMAN: $239-250$ & $\begin{array}{r}\text { ISSN: 2339-0042 (p) } \\
\text { ISSN: 2528-1577 (e) } \\
\text { DOI: 10.24198/share.v10i2.31131 }\end{array}$ \\
\hline
\end{tabular}

menjembatani (bridging), bonding biasanya ditemukan pada kelompok yang homogen sementara bridging akan ditemukan pada kelompok masyarakat yang heterogen (Hasbullah, 2006). Umumnya, masyarakat yang memiliki kapital sosial yang baik dan kuat akan diuntungkan dalam menjalankan proses pembangunan sosial baik itu di masyarakat yang Homogen maupun di masyarakat Heterogen.

Kampung Wapeko di distrik Kurik, Kabupaten Merauke, Papua merupakan salah satu contoh wilayah di Indonesia yang memiliki masyarakat heterogen. Jumlah penduduk kampung Wapeko adalah sekltar 79 KK dengan jumlah jiwa 267 jiwa, 69 KK merupakan warga suku Marind Anim (Orang Asli Papua - OAP) dan 10 KK lainnya merupakan orang pendatang/transmigran (Yasanto, 2015). Warga kampung Wapeko dari suku Marind Anim (OAP) yang secara turun temurun masih berada di pola kehidupan berburu - meramu untuk kemudian bahu-membahu meraih kebermanfaatan dari usaha pertanian modern serta berusaha kompromi dengan warga pendatang/transmigran untuk berbagi kesempatan berekonomi diwilayahnya.

Berbeda dengan OAP, Warga pendatang/transmigran di kampung Wapeko memiliki taraf ekonomi lebih baik dan juga mampu memanfaatkan kapital sosial yang dimilikinya. Hal ini menyebabkan adanya hubungan yang bersifat vertikal antara warga asli suku Marind dan pihak pendatang/transmigran tersebut. Pihak suku Marind menjadikan para pendatang ini sebagai role model dalam pencapaian kondisi kesejahteraan, sesuatu hal yang dalam kapital sosial masuk ke dalam dimensi vertikal.

Penelitian yang dilakukan oleh UNESCO mengenai Social Capital and Poverty Reduction menyatakan bahwa kapital sosial juga memiliki dimensi vertikal yaitu kemiskinan sebagian besar merupakan fungsi dari ketidakberdayaan dan pengucilan, dan sebagai tugas kunci bagi praktisi pembangunan dan pembuat kebijakan adalah memastikan bahwa kegiatan orang miskin tidak hanya "menjangkau", tapi juga juga "ditingkatkan". Uraian tersebut menegaskan apabila warga suku Marind kampung Wapeko sebagai lapisan bawah ingin menjangkau dan meningkatkan kesejahteraan hidup maka harus bisa menjangkau lapisan atas yang berwenang dan bisa menjamin distribusi ekonomi mereka untuk menjadi lebih baik, seperti warga pendatang, pemerintah dan aparat desa.

Tujuan penelitian ini adalah untuk mendeskripsikan dan menganalisis gambaran bentuk kapital sosial masyarakat orang asli papua dan transmigran di kampung Wapeko serta dukungan kapital sosial yang terbentuk dari kedua masyarakat tersebut dalam pengentasan kemiskinan di kampung Wapeko.

\section{METODE PENELITIAN}

Penelitian ini dilakukan warga di kampung Wapeko, Merauke - Papua yang masyarakatnya terdiri dari OAP dan transmigran. Pendekatan penelitian yang dipakai adalah pendekatan kualitatif deskriptif.

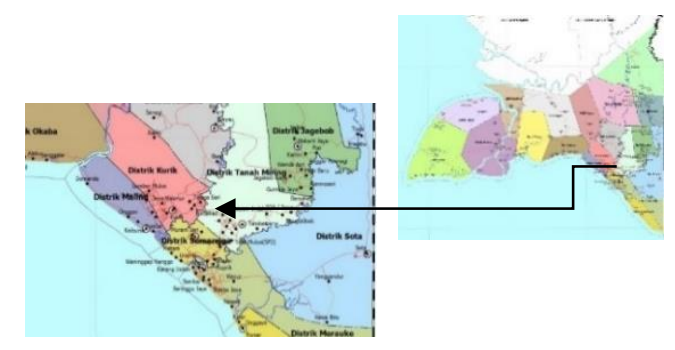

Dalam penelitian kualitatif yang dilakukan, penulis mengacu pada penjelasan (Creswell, 2007) yang menekankan bahwa prosedur penelitian kualitatif ataupun metodologinya dicirikan dengan induktif, yang muncul dan dibentuk oleh pengalaman peneliti dalam mengumpulkan dan menganalisis data. Secara langsung, penelitian di kampung Wapeko mengikuti prosedur penelitian yang menghasilkan data deskriftif berupa kata-kata tertulis atau lisan dari orang-orang atau perilaku yang dapat diamati (Bogdan dan Tylor, 1990).

Adapun metode penelitian yang digunakan adalah studi kasus Prospektif (Prospective Case Study). Jenis Studi Kasus ini diperlukan untuk menemukan kecenderungan dan arah perkembangan dari kasus capital sosial yang ada di Wapeko sebagai lokasi penelitian yang dipilih. Selanjutnya, temuan dan hasil dari penelitian tersebut sebaiknya diperkuat oleh Penelitian Tindakan (Action Research) yang dilakukan oleh pihak lain yang berkompeten. 


\begin{tabular}{|c|c|c|c|c|}
\hline Share: Social Work Jurnal & VOLUME: 10 & NOMOR: 2 & HALAMAN: $239-250$ & $\begin{array}{r}\text { ISSN: 2339-0042 (p) } \\
\text { ISSN: 2528-1577 (e) } \\
\text { DOI: 10.24198/share.v10i2.31131 }\end{array}$ \\
\hline
\end{tabular}

\section{HASIL PENELITIAN}

Bahasan penelitian ini mengikuti alur pemikiran sebagai berikut :

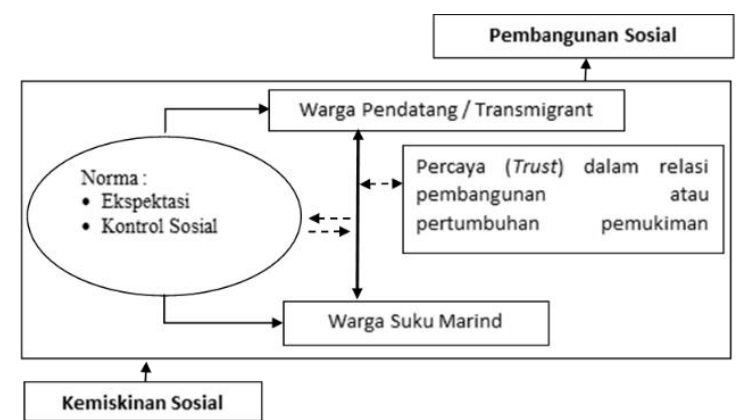

Uraian penelitian terdiri dari dua bagian, pertama yaitu kapital sosial dalam kehidupan orang asli Papua dan transmigran di Wapeko. Bagian ini mengupas tentang kemiskinan dan pembangunan sosial serta bentuk kapital sosial yang ada di Wapeko. Kemudian bagian kedua, dukungan kapital sosial dalam proses pembangunan serta pertumbuhan pemukiman transmigran di Wapeko. Kupasannya difokuskan kepada kontribusi kapital sosial di Wapeko dalam relasi pembangunan dan pertumbuhan pemukiman warga transmigran.

\section{Kapital Sosial dalam kehidupan Orang Asli Papua dan Transmigran di Wapeko.}

Penelusuran kapital sosial masyarakat kampung Wapeko dapat dilihat dari 3 hal yaitu: Sejarah dan perkembangan pembangunan kampung Wapeko, Kondisi Adat dan Budaya Kampung Wapeko, Integrasi Transmigran dalam kehidupan Orang Asli Papua di kampung Wapeko.

1. Sejarah dan perkembangan pembangunan kampung Wapeko.

Terbentuk jauh sebelum tahun 1920, Wapeko awalnya dikenal dengan nama Kampung Senam namun akibat adanya perang saudara dengan kampung Baad, akhirnya banyak warga kampung Senam yang pergi dan menetap di kampung Ivimahad. Kampung Wapeko mulai kembali terbentuk ketika bupati Merauke pada tahun 2002, Johanes Gluba Gebze, membuat kebijakan untuk mengembalikan warga kampung Wapeko di kampung Ivihamad ke wilayah adat mereka di kampung Wapeko, termasuk hak adat atas tanah. Warga asli kampung Wapeko adalah orang papua dari kelompok marga Marind yang terdiri dari 5 sebaran marga yaitu Basik-basik, Balagaise, Ndiken, Mahuse, Samkakai. Berbicara tentang wilayah adat yang dihuni suku Malind Anim, khusus untuk kampung baru Wapeko, tidak semua warganya adalah orang pribumi suku Malind namun ada juga orang transmigran dari luar Papua sebanyak $16 \mathrm{KK}$. Mereka adalah pendatang yang diminta warga Malind Anim secara khusus untuk mendampingi masyarakat Wapeko dalam bertani.

"Kampung Wapeko waktu dulu adalah hutan dan rawa yang baru dibuka, orang malind perlu bantuan untuk bisa mengolah tanah, mereka ndak mampu bertani karena hidupnya berburu di hutan dan jala ikan saja, jarang bertemu orang luar suku, jadinya mereka pemalu dan merasa rendah diri, padahal orang Marind itu kalau sudah ketemu orangnya ramah. 2006 - 2007, kami transmigran dari Salor akhirnya diminta untuk bisa pindah ke sini, bantu mereka olah lahan dan dampingi bertani, ada 16 keluarga dari suku Jawa yang sanggup...."(CR, 25/6/2020).

Kesejahteraan masyarakat kampung Wapeko agak berbeda antara orang Papua dan non Papua, orang Papua (Marind) masih berprofesi sebagai subsisten atau peramu, dimana sehari-hari mereka menggantungkan hidup dari sumber daya alam yang ada, yaitu hutan, rawa-rawa dan sungai. Sebagai pemilik tanah adat, mereka belum mengolah sumber daya alam yang mereka miliki. Hal tersebut karena tidak adanya kemampuan teknis dan jaringan dalam pengelolaan alam (bertani, berdagang) pada kelompok ini. Kondisi tersebut menyebabkan orang papua (Marind) hanya mampu memiliki kebutuhan dasar hidup (rumah, listrik, air bersih, dan lain sebagainya) yang terbatas. Sedangkan ekonomi orang non Papua (orang Jawa dan Makassar) umumnya cukup baik dan tingkat kesejahteraan keluarganya juga lebih baik. Hal ini disebabkan mereka rajin mengelola rawa-rawa yang ada menjadi sawah. Selain itu, dengan jaringan yang dimiliki, orang non papua mampu mengembangkan ekonomi dari sumber mata pencaharian yang lebih variatif, salah satunya dengan membuka warung untuk berdagang barang kebutuhan harian/kelontong (terdapat 2 warung di Wapeko yang dikelola oleh orang non Papua).

\section{Kondisi Adat dan Budaya Kampung Wapeko}




\begin{tabular}{|c|c|c|c|c|}
\hline Share: Social Work Jurnal & VOLUME: 10 & NOMOR: 2 & HALAMAN: $239-250$ & $\begin{array}{r}\text { ISSN: 2339-0042 (p) } \\
\text { ISSN: 2528-1577 (e) } \\
\text { DOI: 10.24198/share.v10i2.31131 }\end{array}$ \\
\hline
\end{tabular}

Mengupas tentang adat budaya Merauke, terdapat istilah ANIMHA. Terjemahan dari ANIM adalah manusia, dan $\mathrm{Ha}$ artinya Sejati. ANIMHA adalah Manusia Sejati atau Manusia Betul. Pengertian Manusia Sejati adalah manusia yang menyatu dengan alam, manusia yang punya tanah dan hutan adat, punya adat istiadat, punya sejarah, punya silsilih, punya leluhur, dan punya segalanya. Dengan kata lain, Animha merefleksikan "tuan diatas tanahnya sendiri". Terkait marga di Wapeko, saat ini yang menguasai sebagian besar lahan berasal dari marga Gebze sub marga Samkakai. Penguasaan lahan ini memberikan akses ekonomi dan juga posisi secara kesukuan di struktur adat Wapeko. Untuk memahami posisi marga/fam suku Marind, bisa dilihat pada data yang tersaji di tabel berikut ini :

Tabel 1. Marga dan Totem ANIMHA

\begin{tabular}{|c|l|l|}
\hline MARGA & \multicolumn{1}{|c|}{ SUBMARGA } & \multicolumn{1}{|c|}{ REMARKS } \\
\hline 1. GEBZE (Kelapa) & $\begin{array}{l}\text { Gablik, Ohanlik, Awabalik, } \\
\text { Namelalik, Kuyamlik, } \\
\text { Samkakai }\end{array}$ & $\begin{array}{l}\text { Gablik : penguasa, Ohanlik : kumpulan } \\
\text { berburu, Awabalik : bagaikan perahu, } \\
\text { Namelalik : wakil Gablik; Kuyamlik : perahu } \\
\text { golongan Imo, Samkakai : kangguru }\end{array}$ \\
\hline $\begin{array}{c}\text { 2. KAIZE (Burung } \\
\text { Kasuari) }\end{array}$ & $\begin{array}{l}\text { Honilik, Saulamlik, } \\
\text { Daboyaslik, Beramik }\end{array}$ & $\begin{array}{l}\text { Honilik : turunan kasuari; Saulamlik : } \\
\text { kecantikan; Daboyaslik urusan orang } \\
\text { Wendu, Beramik : termasuk orang Salor }\end{array}$ \\
\hline $\begin{array}{c}\text { 3. NDIKEN (Burung } \\
\text { Dig) }\end{array}$ & Malindlik, Yawimalik \\
\hline $\begin{array}{l}\text { 4. MAHUZE } \\
\text { (Totemnya Mahu) }\end{array}$ & $\begin{array}{l}\text { Diwalik, Aluan, Wakabulik, } \\
\text { Maliulik, Kanaze, } \\
\text { Bagause, Makasih, Zohelik }\end{array}$ & $\begin{array}{l}\text { Diwalik : manusia pemimpin, Aluan : } \\
\text { bagaikan perahu }\end{array}$ \\
\hline $\begin{array}{c}\text { 5. BASIK-BASIK } \\
\text { (Totemnya NATZ) }\end{array}$ & $\begin{array}{l}\text { Nazelik, Sapilik, Balagaize, } \\
\text { Safarlik, }\end{array}$ & $\begin{array}{l}\text { Nazelik : manusia tinggal di Takuar, Sapilik: } \\
\text { babi menjadi perintis; Balagaize : bagaikan } \\
\text { perahu, Safarlik : manusia }\end{array}$ \\
\hline
\end{tabular}

Sumber: Olahan Penelitian

Marga tersebut penting untuk pengaturan penguasaan lahan. Kepemilikan tanah adat orang Marind berdasarkan marga dengan batas-batas yang sudah jelas diantara mereka. Artinya tanah adat bukan milik sub suku atau suku tetapi sepenuhnya berada pada setiap marga dan batasbatas wilayah adat per-marga ditandai secara alam, seperti batu, pohon, sungai, rawa-rawa dan dusun-dusun sagu. Bahkan dalam aturan adat, tidak dibenarkan orang luar atau dari marga lain memasuki hutan dari marga lainnya, bila ini dilanggar maka ada sanksi adat atau dapat menimbulkan konflik yang dapat saja berupa terjadinya pertikaian dan mengakibatkan korban nyawa diantara mereka. Batas wilayah tanah adat Wapeko diketahui berbatasan dengan tanah adat Ivimahad (Salor), tanah adat kampung Kaliki, dan tanah adat kampung Baad.
Adat budaya suku Marind memiliki dan menerapkan konservasi tradisional yang telah dilakukan secara turun temurun dari leluhur mereka. Sistem pelestarian alam ini terlihat pada tata cara pengambilan kayu-kayu untuk kepentingan kontruksi bangunan dimana jenis yang diambil adalah kayu tertentu dan diberlakukan pilih tebang. Selain itu, terdapat juga tempat-tempat sakral yang dijaga oleh marga, sub suku atau suku dengan aturan dan sanksi adat. Umumnya tempat-tempat sakral ini masih terjaga dan terawat secara alami sehingga tumbuhan dan satwa yang berada dalam areal sakral tersebut habitat dan ekosistemnya masih terjaga dengan baik. Mereka juga mengenal budaya "sasi" (larangan/batasan) yang diberlakukan pada hutan, kali dan rawa yang menjadi tempat hidup berbagai jenis keanekaragaman hayati yang bermanfaat (ekonomi, obat-obatan dan ritual adat). 


\begin{tabular}{|c|c|c|c|c|}
\hline Share: Social Work Jurnal & VOLUME: 10 & NOMOR: 2 & HALAMAN: $239-250$ & $\begin{array}{r}\text { ISSN: 2339-0042 (p) } \\
\text { ISSN: 2528-1577 (e) } \\
\text { DOI: 10.24198/share.v10i2.31131 }\end{array}$ \\
\hline
\end{tabular}

Khususnya spesies yang menunjang perekonomian mereka pada daerah rawa-rawa dan kali seperti berbagai jenis ikan, kura-kura, buaya dan udang. Sedangkan di hutan seperti; Babi, Rusa, Saham (kanguru), kaswari, tuban (tikus hutan) dan lainnya.

3. Integrasi Transmigran dalam kehidupan Orang Asli Papua di kampung Wapeko

Keberadaan warga transmigran di kampung Wapeko tidak terlepas dari permintaan orang Marind agar mereka bisa mendampingi dan mengajarkan bertani kepada mereka. Kemampuan bercocok tanam yang memang dibawa serta para transmigran dari daerah asal dipandang dapat membantu meningkatkan taraf hidup orang asli Papua di Wapeko. Etos kerja warga transmigranmigrasi yang baik dalam mengolah lahan dan bertani membuat warga asli suku Marind tertarik dan ingin belajar dari warga trasnmigran. Bahkan ada beberapa warga yang diberikan hak sewa untuk menggarap lahan milik warga Marind untuk dijadikan persawahan. Sistem sewa berbentuk pembayaran di muka untuk per ha selama satu tahun, nilainya berkisar antara 200 - 500 ribu, tergantung negosiasi dan kedekatan dengan pemilik lahan.

Saat ini, selain berburu dan pancing/jala ikan, bertani menjadi salah satu bagian dari mata pencaharian beberapa warga Marind di kampung Wapeko. Kemampuan bertani mereka meningkat selain karena bimbingan warga transmigran juga karena adanya balai benih pertanian yang dibangun pemerintah di dekat pemukiman kampung Wapeko. Keberadaan warga transmigranmigrasi juga membantu warga Marind dalam memenuhi kebutuhan hidupnya. Di Wapeko, warga transmigranmigrasi merupakan kelompok masyarakat yang menginisiasi untuk mendirikan warung di kampung, karena sebelumnya warga Marind tidak mengenal warung dan terbiasa memenuhi semua kebutuhan mereka degan mengambil dari hutan dan bukan lewat jual-beli. Dengan adanya warung tersebut, orang Marind dan transmigran yang membutuhkan keperluan harian dan bahan bakar kendaraan/genset, tidak perlu pergi dulu ke Kurik yang jaraknya diatas $40 \mathrm{~km}$ dari Wapeko.

Orang Marind juga memperbolehkan seorang warga transmigran yang juga guru di SDN Wapeko untuk menjualkan hasil tangkapan ikan mereka ke wilayah lain di luar Wapeko. Awalnya bayar ikan kepada orang Marind dilakukan setelah ikan terjual di Kurik atau Merauke. Seiring waktu, pembayaran bisa dilakukan terlebih dahulu karena ketersediaan modal beli dari warga transmigran, ini setara dengan jual beli putus. Pola penjualan melalui warga transmigran tersebut membuat warga Marind diuntungkan karena tidak harus bersusah payah membawa ikan ke tempat lain dan tidak perlu juga melakukan negosiasi jual beli ketika transmigranaksi, sebuah hal yang tidak dikuasai oleh orang suku.

\section{Dukungan Kapital Sosial dalam proses pembangunan serta pertumbuhan pemukiman transmigran di Wapeko.}

Dua hal yang menjadi perhatian penting bagi kalangan pendatang di Merauke adalah soal kepemilikan lahan untuk menjalankan kehidupan dan juga meningkatnya taraf penghidupan yang dimiliki agar dapat memperoleh kesejahteraan yang baik. Hubungan yang kemudian tercipta antara warga transmigran dan orang asli Papua di Wapeko pada akhirnya memiliki andil dalam mewujudkan dua hal tersebut.

a. Penyelesaian konflik Tenurial di kampung
Wapeko

Terdapat suatu tradisi dalam masyarakat suku Marind bahwa tanah yang belum dilepas dengan menggunakan upacara adat bunuh/pukul babi, dianggap belum sah sekalipun telah dibeli dengan harga yang telah disepakati dan sudah disertifikatkan. Hal ini dikarenakan suatu saat nanti anak cucu dari pemilik tanah adat tersebut akan menuntut kembali tanah tersebut karena dianggap masih milik marga. Pemalangan tanah karena peristiwa seperti ini sudah sangat umum terjadi di Papua, khususnya Merauke. Keberadaan sertifikat Hak Milik yang memiliki kekuatan hukum secara nasional tidak punya arti apa-apa ketika berhadapan dengan prinsip ulayat marga yang mereka yakini dan pegang teguh.

Berbicara mengenai pemanfaatan lahan, tanah di wilayah adat Kampung Wapeko sangat potensial untuk pengembangan pertanian, areal rendah dan rawa - rawa musiman sangat cocok untuk pengembangan padi sawah tadah hujan, dan didaerah - daerah tinggi cocok untuk tanaman palawija serta tanaman keras. Produksi 


\begin{tabular}{|c|c|c|c|c|}
\hline Share: Social Work Jurnal & VOLUME: 10 & NOMOR: 2 & HALAMAN: $239-250$ & $\begin{array}{r}\text { ISSN: 2339-0042 (p) } \\
\text { ISSN: 2528-1577 (e) } \\
\text { DOI: 10.24198/share.v10i2.31131 }\end{array}$ \\
\hline
\end{tabular}

padi per hakter di Wapeko bervariasi antara $2 \mathrm{~s} / \mathrm{d}$ 5 ton/ha. Luas lahan yang dipergunakan untuk

sawah di Wapeko dapat dilihat dari tabel berikut :

Tabel 2. Data Pengelolaan Sawah di Wapeko (2019)

\begin{tabular}{|c|l|c|}
\hline No. & \multicolumn{1}{|c|}{ Kategori } & Luas (Ha) \\
\hline 1. & PT Parama Pangan & 600 \\
\hline 2. & PT Sawah Indah Lestari & 100 \\
\hline 3. & Petani mitra & 387 \\
\hline 4. & Masyarakat Wapeko & 26 \\
\hline 5. & Petani di area Apar & 187 \\
\hline \multicolumn{2}{|c|}{ Total } & 1.250 \\
\hline
\end{tabular}

Sumber : Olahan penelitian

Proses sewa lahan yang dilakukan warga Marind dengan perusahaan ini membuka jalan bagi warga diluar orang asli Papua untuk lebih mudah mendapatkan lahan sewa dari orang suku. Tidak saja bagi warga transmigran di Wapeko tapi juga di kampung lainnya seperti dari Salor. Selain proses sewa, ada juga yang berhasil melakukan jual beli lahan dengan pihak orang Marind, jumlahnya juga termasuk cukup luas. Mereka melakukan jual beli lahan tersebut dengan mengikuti syarat pelepasan tanah berdasar adat suku Marind yaitu upacara pukul babi. Menurut orang Marind di Wapeko, lahan sewa ini jauh lebih menguntungkan daripada membiarkan tanah hanya ditumbuhi pohon-pohon kayu yang tidak bisa dimanfaatkan untuk kebutuhan sehari-hari.

\section{b. Peningkatan penghidupan (Livelihood) di kampung Wapeko}

Pendapatan masyarakat Wapeko tergolong relatif berbeda-beda antar setiap keluarganya. Hal ini menyebabkan sulitnya mengambil satu nilai rata-rata pendapatan mereka secara keseluruhan, begitu pula dengan pengeluarannya. Dari beberapa informan yang secara detail menjawab pertanyaan soal ini, ada perbedaan dalam soal pendapatan dan pengeluaran setiap bulannya. NKS, misalnya, bermata pencaharian sebagai petani di lahan sendiri yang menggarap 1,5 $\mathrm{Ha}$. Total pendapatan yang diterima setiap musim tanam adalah $\mathrm{Rp}$ 15.000.000/ musim tanam. Sementara itu dari pekerjaan sampingan (menanam sayur-sayuran seperti daun singkong, kacang panjang, terong) yang dikerjakan bersama keluarga, diperoleh tambahan sekitar Rp. 5.000.000. Pengeluaran rumah tangga NKS yang rutin total setiap hari kurang lebihnya Rp. 100.000,. Dalam sebulan pengeluaran rumah tangga NKS paling sedikit adalah Rp. 3.000.000,-. Keluarga yang berasal dari suku Marind ini belum memanfaatkan jasa perbankan baik dalam menjalankan usaha mereka maupun juga untuk menabung.

Informan PG memiliki pekerjaan menangkap ikan di rawa. Penghasilan informan dari menangkap ikan tidak menentu sebulan jika diratarata ikan hasil tangkapannya bisa mencapai 200 ikan, dan dijualnya 1 ikan sama dengan 1 tusuk dengan harga 10ribu/ tusuknya. Jadi jika ditotal penghasilannya 2.000.000 per bulan itu tidak menentu. Pekerjaan sampingan dari informan warga Marind di Wapeko ini adalah berburu dengan hasil yang didapat tidak pasti. Kadang sebulan dari berburu hanya mendapatkan 2 ekor rusa dan penghasilan dari berburu tersebut kurang dari 1.000.000. Selama ini belum ada bantuan dari pihak pemerintah maupun perusahaan swasta.

Keluarga SW yang merupakan warga transmigran yang bermata-pencaharian sebagai petani padi, memperoleh pendapatan rata-rata sebulannya Rp 7.312.500. Pada musim kemarau keluarga mempunyai pekerjaan sampingan sebagai pengepul ikan yang dibeli dari masyarakat seharga Rp. 15.000/ikat dan dijual ke Salor Rp. 18.000/ikat. Rata-rata pendapatan yang dapat diperoleh SW sebulan dari pengepul ikan adalah sebanyak Rp. 4 juta. Pendapatan total yang diterima keluarga ini dari pekerjaan utama dan sampingan selama sebulan adalah Rp. 11.312.500. Sementara pengeluaran sebulan untuk kebutuhan rumah tangga dan sekolah anak terdata sebesar Rp 4,5 juta/bulan. Sisa pendapatan SW ini tergolong 


\begin{tabular}{|c|c|c|c|c|}
\hline Share: Social Work Jurnal & VOLUME: 10 & NOMOR: 2 & HALAMAN: $239-250$ & $\begin{array}{r}\text { ISSN: 2339-0042 (p) } \\
\text { ISSN: 2528-1577 (e) } \\
\text { DOI: 10.24198/share.v10i2.31131 }\end{array}$ \\
\hline
\end{tabular}

cukup besar sehingga ada sebagian yang ditabung dan sebagian lagi digunakan untuk modal usaha sampingan sebagai pengepul. Menurut SW, mereka hingga hari ini belum memanfaatkan dan juga belum pernah menerima bantuan pinjaman dari pemerintah/perbankan.

Keberadaan kelompok pedagang yang banyak berasal dari warga transmigran, dirasa sangat membantu perekonomian warga setempat terutama bagi warga suku yang bermata pencaharian petani, berburu dan menangkap ikan. Walau tidak ada aturan yang tertulis yang mengatur hubungan antar mereka, tetapi kebersamaan dan saling mengerti satu sama lain tetap dijaga. Di dalam kampung, karena aturan adat masih dipegang erat, keputusan yang diambil dikampung adalah keputusan yang dibuat bersama dalam marga (adat) yang terdapat di kampung Wapeko. Keputusan ini sifatnya mengikat untuk seluruh warga Wapeko baik yang orang Marind maupun pendatang.

\section{DISKUSI.}

Bentuk kapital sosial masyarakat Orang Asli Papua (OAP) dan Transmigran di Kampung Wapeko, Distrik Kurik, Kab. Merauke Papua

Berdasarkan dari hasil penelitian, bahwa kepindahan warga Marind ke kampung Wapeko dari Ivimahad harus dimulai dengan mengolah hutan dan rawa yang baru dibuka, kehidupan yang dialami waktu itu sangatlah sulit. Ini menyebabkan kemampuan untuk penghidupan kampung yang layak menjadi terkendala karena praktis diantara warga kampung yang berasal dari suku Marind tidak memiliki kemampuan kuat dalam urusan pemanfaatan alam selain secara meramu atau berburu. Pada posisi ini, kemiskinan sosial yang didefinisikan "Seseorang dikatakan miskin secara sosial, jika tidak memiliki modal sosial vertikal maupun horizontal (dalam arti positif) yang berdampak pada kemampuannya untuk mendorong mobilitas sosial vertikal" (Lawang, 2018), terjadi di kalangan warga suku Marind kampung Wapeko.

Upaya warga suku Marind Wapeko untuk bisa maksimal mendayagunakan sumber alam yang dimiliki, diyakini hanya mampu dilakukan apabila ada bantuan dari pihak lain diluar komunitasnya. Upaya mengakses sistem sumber diluar komunitas warga Marind wapeko tersebut tidak memiliki banyak pilihan, hanya ada dari pihak pemerintah dan juga komunitas transmigran. Pemerintah hanya menyediakan pengembalian lahan adat, pembukaan hutan dan rawa, serta pembangunan rumah sederhana. Sementara untuk matapencaharian, setelah beberapa waktu mendiami kampung, mereka hanya mampu meminta agar ada warga transmigran yang bisa tinggal dan mengajari pertanian. Kurangnya akses ke kelompok lain di luar kelompoknya seperti yang terjadi di Warga Marind Wapeko, merupakan kondisi kemiskinan sosial seperti yang disampaikan pada landasan teoritis dimana Lewandowsky menyoroti kemiskinan sosial karena terkait kelangkaan modal sosial vertikal dan koneksi.

Dalam kehidupan sosialnya, warga Marind selalu menjunjung tinggi aturan marga, pengaturan kekerabatan, pengaturan kepemilikan dan pengelolaan lahan, konsensus tentang pusaka keluarga (tanaman wati) dan juga aturan berburu, pemanfaatan hutan serta konservasi tradisional (sasi) yang ada selalu menjadi acuan hidup keseharian mereka dan ditujukan agar kehidupan sebagai peramu - pemburu tetap dapat dijalankan oleh orang Marind sekaligus agar dapat memenuhi kebutuhan hidup kelompoknya tersebut. Inilah yang menurut (Coleman, 1999) disebut kondisi dari keberadaan kapital sosial, dijabarkan sebagai kemampuan masyarakat untuk bekerja bersama, demi mencapai tujuan bersama, di dalam berbagai kelompok dan organisasi.

Merujuk kepada pengertian kapital sosial dari Cox (1995) serta Fukuyama (1995) yang diperkuat Cohen dan Prusak L (2001), warga Marind di Wapeko jelas memiliki kepercayaan kuat antar anggota kelompoknya (perlindungan marga dan hak anggotanya), norma yang ditaati bersama tanpa kecuali (kekerabatan, pembagian dan pengelolaan lahan, berburu, pemanfaatan hutan dan konservasi tradisional) serta saling pengertian yang memperkuat jaringan (hukum adat diutamakan daripada hukum positif). Kapital sosial yang ada di masyarakat Marind sifatnya mengikat tanpa kecuali untuk orang Marind di Wapeko dan bersifat eksklusif, ini menegaskan tipologi kapital sosial yang ada di masyarakat tersebut termasuk kedalam kapital sosial terikat (bonding). Tipologi ini sesuai dengan karakteristik yang dikemukakan oleh (Hasballah, 2006) yaitu kapital sosial yang lebih berorientasi ke dalam (inward looking) 


\begin{tabular}{|c|c|c|c|c|}
\hline Share: Social Work Jurnal & VOLUME: 10 & NOMOR: 2 & HALAMAN: $239-250$ & $\begin{array}{r}\text { ISSN: 2339-0042 (p) } \\
\text { ISSN: 2528-1577 (e) } \\
\text { DOI: 10.24198/share.v10i2.31131 }\end{array}$ \\
\hline
\end{tabular}

dibandingkan dengan berorientasi keluar (outward looking).

Tipologi inilah kemudian yang menyulitkan orang Marind di Wapeko untuk dapat menghadapi perubahan kondisi kampung dari bentuk kehidupan tradisional (kehidupan pemburu - peramu) menuju kehidupan modern (pertanian - perdagangan) karena kapital sosial yang dimiliki tidak mampu menggapai kapital sosial dari kelompok lain yang permisif terhadap kehidupan modern, meskipun sekarang jauh lebih banyak warga Marind yang mau membuka diri pada penduduk luar agar mereka dapat mengembangkan usaha pertanian yang mereka miliki. Pada tahap ini, bentuk kapital sosial terikat (bonding) dari orang Marind di Wapeko mulai bertransmigranformasi ke bentuk kapital sosial yang menjembatani (bridging social capital) dengan munculnya kepercayaan (trust) terhadap kelompok lain (transmigran) walaupun diawali hanya terbatas dalam urusan pengelolaan lahan.

Berbeda dengan warga Marind, warga transmigran di Wapeko sebagai warga pendatang memiliki keterikatan yang kuat antar sesama warga transmigran dan mereka pun sangat kompak bergotong royong membantu mengembangkan usaha mereka baik dibidang pertanian maupun perdagangan. Warga transmigran juga lebih terbuka dalam menjalin komunikasi dengan pihak luar dibanding warga Marind. Jaringan luas yang dimiliki warga transmigran dan adanya kebutuhan warga Marind yang hanya bisa disediakan oleh warga transmigran menciptakan hubungan saling membutuhkan. Warga transmigran butuh keamanan dan lahan dimana hal itu hanya bisa diberikan oleh warga Marind sebagai orang asli dan warga marind sendiri juga butuh ilmu pertanian dan perdagangan dari warga transmigran agar taraf hidup mereka dapat meningkat. Heterogenitas pola hubungan kelompok Transmigran dalam menjalani kehidupan kesehariannya di Wapeko, secara persfektif tipologi kapital sosial dari Haines (2002:104) termasuk merupakan bentuk kapital sosial yang menjembatani (Bridging Social Capital).

Pada akhirnya, sesuai dengan yang dikemukakan Hasbullah (2006), kapital sosial menjembatani (bridging) yang ada di kelompok transmigran Wapeko membuka jalan bagi kelompok ini untuk dapat lebih cepat berkembang dengan kemampuan interaksi untuk menciptakan jaringan (networking) yang kuat, menggerakkan identitas yang lebih luas dan timbal balik (reciprocity) yang lebih variatif. Interaksi yang intens dan konsisten pada akhirnya mendorong untuk terciptanya saling percaya (trust).

Dalam penelitian ini, diperoleh temuan bahwa kelompok transmigran menerapkan norma kerjasama (gotong royong) dan etos kerja pantang menyerah yang dimilikinya untuk dapat menumbuhkan rasa percaya (trust) dari orang Marind. Etos kerja pantang menyerah ini diterapkan dalam menjalankan harapan awal orang Marind ketika meminta warga transmigran untuk pindah ke Wapeko yaitu mendampingi dan mengajarkan bertani kepada mereka. Ketelatenan dan kesabaran yang merupakan cerminan etos kerja pantang menyerah warga transmigran menghasilkan keberhasilan panen pada lahan yang diolah bersama dengan warga Marind.

Pada titik tersebut, muncul rasa yakin dari orang Marind akan kemampuan bertani yang dimiliki dan juga rasa terimakasih kepada warga transmigran atas jasa mengajar dan mendampingi mereka. Elemen rasa terimakasih menciptakan unsur percaya (trust) dari orang Marind di Wapeko kepada keberadaan orang transmigran dalam membantu mereka untuk keluar dari ketidakmampuan penghidupan ekonomi. Temuan selanjutnya adalah bahwa percaya (trust) yang terbangun ini semakin mengukuhkan keberadaan jaringan (networking) antara warga transmigran dan orang Marind, penguatan identitas warga transmigran sebagai bagian integral dari masyarakat kampung Wapeko serta adanya timbal balik (reciprocity) yang lebih banyak dalam urusan akses terhadap sumber daya yang dimiliki kampung Wapeko.

\section{Dukungan Kapital Sosial dalam proses pembangunan serta pertumbuhan pemukiman transmigran di Wapeko.}

Pembangunan serta pertumbuhan pemukiman transmigranmigrasi di kampung Wapeko tidak lepas dari adanya kebutuhan warga Marind terhadap warga pendatang agar mereka dapat meningkatkan keemampuan bertani mereka dan meningkatkan taraf hidup mereka. Berikut adalah dua faktor yang menyebabkan warga Marind membuka diri terhadap warga transmigran:

1. Pemahaman warga Marind kalau lahan sewa ini jauh lebih menguntungkan daripada 


\begin{tabular}{|c|c|c|c|c|}
\hline Share: Social Work Jurnal & VOLUME: 10 & NOMOR: 2 & HALAMAN: $239-250$ & $\begin{array}{r}\text { ISSN: 2339-0042 (p) } \\
\text { ISSN: 2528-1577 (e) } \\
\text { DOI: 10.24198/share.v10i2.31131 }\end{array}$ \\
\hline
\end{tabular}

membiarkan tanah hanya ditumbuhi pohonpohon kayu yang tidak bisa dimanfaatkan untuk kebutuhan sehari-hari. Kesediaan warga untuk meminjam pakaikan tanahnya kepada perusahaan dan juga warga transmigran didukung oleh fakta bahwa sekarang anak-anak orang Marind sudah banyak yang tidak lagi makan sagu, tetapi sudah lebih sering makan nasi.

2. Sistem lahan sewa membuat potensi peningkatan kapital finansial dari warga transmigran di Wapeko dan juga kampung lainnya menjadi terbuka lebar karena ketersediaan lahan usaha pertanian yang lebih luas yang bisa diperoleh tanpa harus melalui pelepasan hak kepemilikan (upacara bunuh/pukul babi) yang berbiaya besar.

Fakta lapangan selanjutnya dari penelitian ini menunjukkan munculnya aturan (norms) baru di kampung Wapeko terkait pemanfaatan hutan. Aturan tersebut memastikan kewenangan orang Marind untuk menjadi pihak utama yang melakukan pengelolaan hutan (termasuk konservasi dengan mekanisme sasi) dan pemanfaatannya (berburu, ambil ikan, tebang kayu) sementara warga transmigran diperbolehkan melakukan proses perdagangan hasil hutan tersebut sampai ke luar dari wilayah kampung Wapeko. Dengan demikian, dipastikan terdapat satu jenis matapencaharian lainnya di Wapeko yaitu berdagang selain meramu, berburu, dan bertani.

Warga transmigran yang menjalankan proses berdagang hasil hutan ini kemudian dikenal dengan istilah "pengepul", profesi yang sebelumnya tidak dikenal di kehidupan keseharian orang Marid Wapeko. Disini kemudian muncul proses yang oleh Hasbullah (2006) disebut sebagai timbal balik (reciprocity) dengan efek menguatkan aspek ekonomi antara dua kelompok tersebut. Penguatan yang terjadi pada pihak orang Marind berupa kemampuan mengoptimalkan perolehan hasil hutannya tidak hanya untuk keperluan konsumsi tetapi juga untuk keperluan memenuhi kebutuhan hidup lainnya termasuk menabung sedangkan bagi pihak warga transmigran penguatannya berupa adanya pilihan sumber penghidupan yang lebih bervariasi dan percepatan peningkatan kesejahteraan.
Analisa adanya penguatan tersebut didukung oleh temuan lapangan yang memperlihatkan kemampuan ekonomi yang bertambah baik dari orang Marind maupun transmigran ketika menjalankan peran sebagai pemburu/peramu, petani dan pedagang/pengepul dalam urusan pengelolaan dan pemanfaatan hutan. Kemampuan ekonomi yang meningkat ini bagi pihak warga transmigran juga berarti munculnya kemampuan untuk perbaikan hunian maupun keperluan lainnya seperti pendidikan anak ataupun investasi. Seluruh temuan lapangan terkait urusan pemanfaatan hutan tersebut apabila dikaji merupakan cerminan dari kapital sosial menjembatani (bridging) yang muncul karena menguatnya kepercayaan antara dua kelompok sehingga muncul aturan yang disepakati bersama yang memungkinkan seluruh anggota kelompok tersebut memaksimalkan jaringan yang dimiliki untuk tujuan mencapai penghidupan (livelihood) lebih baik di masa mendatang.

\section{KESIMPULAN}

Kapital sosial yang ada di masyarakat Marind merupakan kapital sosial yang sifatnya mengikat tanpa kecuali untuk orang Marind di Wapeko dan bersifat eksklusif, ini menegaskan tipologi kapital sosial yang ada di masyarakat tersebut termasuk kedalam kapital sosial terikat (bonding) yaitu kapital sosial yang lebih berorientasi ke dalam (inward looking) dibandingkan dengan berorientasi keluar (outward looking). Tipologi Kapital sosial terikat orang Marind menimbulkan kesulitan untuk dapat menghadapi perubahan kondisi kampung dari bentuk kehidupan tradisional menuju modern karena kapital sosial yang dimiliki tidak mampu menggapai secara maskimal kapital sosial dari kelompok lain yang lebih permisif.

Keberadaan kelompok transmigran yang menerapkan norma kerjasama (gotong royong) dan etos kerja pantang menyerah mampu memperkuat jaringan yang mereka miliki sehingga menimbulkan jaringan yang kuat dalam menjalankan beragam variasi mata pencaharian (bertani, berdagang, pegawai) sehingga kondisi ekonominya meningkat. Heterogenitas pola hubungan kelompok Transmigran dalam menjalani kehidupan kesehariannya di Wapeko, secara persfektif tipologi kapital sosial termasuk merupakan bentuk kapital sosial yang menjembatani (Bridging Social Capita). 


\begin{tabular}{|c|c|c|c|c|}
\hline Share: Social Work Jurnal & VOLUME: 10 & NOMOR: 2 & HALAMAN: $239-250$ & $\begin{array}{r}\text { ISSN: 2339-0042 (p) } \\
\text { ISSN: 2528-1577 (e) } \\
\text { DOI: 10.24198/share.v10i2.31131 }\end{array}$ \\
\hline
\end{tabular}

Merunut perkembangan interaksi sosial yang terjadi selanjutnya di kedua kelompok tersebut, terbangun rasa percaya yang bersifat dua arah. Percaya (trust) yang terbangun ini semakin mengukuhkan keberadaan jaringan (networking) antara warga transmigran dan orang Marind, penguatan identitas warga transmigran sebagai bagian integral dari masyarakat kampung Wapeko serta adanya timbal balik (reciprocity) yang lebih banyak dalam urusan akses terhadap sumber daya yang dimiliki kampung Wapeko. Timbal balik ini secara langsung mempermudah proses peningkatan pembangunan penghidupan maupun pertumbuhan pemukiman dari masyarakat transmigran di Wapeko sehingga mereka bisa menggapai taraf kesejahteraan yang lebih baik lagi di masa mendatang.

Terkait tujuan kedua dari penelitian yaitu dukungan kapital sosial yang terbentuk dari kedua masyarakat tersebut dalam pembangunan serta pertumbuhan pemukiman transmigran di Kampung Wapeko maka dapat disimpulkan bahwa kepercayaan yang terbangun pada dua kelompok yang ada di kampung Wapeko berlaku secara dua arah. Orang Marind percaya bahwa warga transmigran mampu mendampingi dan mengajari mereka untuk menguatkan keahlian pertanian dan perdagangan sedangkan warga transmigran percaya orang Marind akan melindungi mereka terkait urusan kepemilikan lahan sepanjang aturan adat dipenuhi. Perkembangan selanjutnya, saling percaya ini mengantarkan warga transmigran untuk dapat mengakses pembagian dan pengelolaan lahan serta pemanfaatan hasil hutan yang porsinya semakin dibuka lebih luas oleh orang Marind (pelepasan kepemilikan dan sewa lahan, pengepul hasil hutan).

Munculnya sistem sewa lahan dan pengepul hasil hutan adalah cerminan timbal balik (reciprocity) dari kepercayaan (trust) yang berkembang antara warga Marind terhadap warga transmigran di Wapeko. Ketika sistem sewa lahan maupun pengepul hasil hutan ini menarik pihak lain di luar warga transmigran Wapeko terutama dari pihak korporasi, terjadi perubahan orientasi tujuannya yang awalnya hanya diposisikan oleh warga Marind sebagai penguat interaksi dengan warga transmigran menjadi lebih mengarah ke dimensi ekonomi. Disinilah kemudian aturan (norms) sistem sewa lahan dan pengepul hasil hutan tersebut sudah bisa disebut sebagai sebuah kapital sosial. Fokus dari tujuan pemanfaatan kapital sosial sewa lahan dan pengepul hasil hutan ini yaitu memposisikan adanya keuntungan bersama yang diperoleh kedua belah pihak dalam upayanya untuk keluar dari struktur kemiskinan yang ada di Wapeko.

Secara keseluruhan, ditarik kesimpulan bahwa kemiskinan sosial yang terjadi pada orang Wapeko disebabkan karena tidak dimilikinya bridging capital social, kondisi tersebut terjadi di kelompok orang Marind. Ketika kemudian kelompok orang Marind melakukan proses menggapai kapital sosial kelompok transmigran di Wapeko sehingga mampu membentuk bridging capital social, perbaikan penghidupan kampung Wapeko juga menjadi berjalan dan menguat.

\section{SARAN}

Berdasarkan uraian kesimpulan di atas, terdapat poin-poin saran yang melingkupi beberapa bidang kegiatan yang dapat diserap dan dijalankan oleh pemerintah, orang Marind dan warga transmigran serta perusahaan pertanian modern yang beroperasi di Kampung Wapeko. Berikut adalah saran tersebut :

1. Rendahnya kapasitas yang dimiliki masyarakat kampung Wapeko memerlukan dilaksanakannya program pelatihan yang terfokus. Bagi masyarakat Marind, pemerintah maupun perusahaan dapat menjalankan program peningkatan keterampilan pemilik hak ulayat masyarakat kampung. Kegiatannya berupa penyelenggarakan pelatihan keterampilan on farm, off farm dan non-farm. Bagai warga transmigran, pemerintah maupun perusahaan dapat menjalankan program pelatihan kewirausahaan. Kontribusi perusahaan dapat berupa bantuan modal dan beasiswa (CSR, donasi).

2. Kelembagaan menjadi pilar penting dalam pembangunan di Wapeko. Hal yang dapat dilakukan pemerintah, perusahaan (CSR) dan pihak - pihak lainnya adalah menginisiasi program peningkatan kapasitas SDM aparat dan kelembagaan pemerintah kampung Wapeko.

3. Penguatan ekonomi masyarakat memerlukan lembaga usaha yang tangguh. Hal yang bisa dijalankan adalah menjalin kerjasama dengan perusahaan (Corporate Social Responsibility) guna memberikan pendampingan dan pelatihan kepada kampung untuk membentuk 


\begin{tabular}{|c|c|c|c|c|}
\hline Share: Social Work Jurnal & VOLUME: 10 & NOMOR: 2 & HALAMAN: $239-250$ & $\begin{array}{r}\text { ISSN: 2339-0042 (p) } \\
\text { ISSN: 2528-1577 (e) } \\
\text { DOI: 10.24198/share.v10i2.31131 }\end{array}$ \\
\hline
\end{tabular}

Badan Usaha Milik Kampung dengan memanfaatkan Dana Desa. Selain itu, masyarakat kampung Wapeko diharapkan dapat membentuk koperasi perempuan (bidang keuangan, sosial, dsb) yang sesuai dengan potensi kampung untuk menampung dan meningkatkan produktifitas perempuan.

4. Dalam kehidupan masyarakat yang heterogen seperti di Wapeko (orang Marind dan transmigran), selalu muncul kecenderungan terjadinya kesenjangan sosial. Pihak pemerintah dan perusahaan diharapkan mampu menjalankan pendekatan khusus yang menyasar lingkup penguatan kohesi sosial dan pembentukan modal sosial. Program dan kegiatan dalam kerangka CSR yang bisa dijalankan perusahaan untuk kohesi sosial adalah berupa pemberian bantuan modal bagi masyarakat asli dan penggarap untuk usaha yang berhubungan dengan operasional perusahaan. Sedangkan bagi pemerintah kegiatan yang bisa dijalankan adalah program integrasi masyarakat pendatang dalam sistem budaya dan sosial masyarakat asli. Terkait modal sosial, pemerintah dapat menjalankan program pembentukan modal sosial yang melibatkan penduduk asli dan pendatang serta kelompok marginal dalam sistem kekerabatan adat, seperti: perempuan dan anak-anak.

\section{UCAPAN TERIMAKASIH}

Penulis mengucapkan terimakasih kepada pihak Medco Foundation dan seluruh masyarakat kampung Wapeko, Distrik Kurik, Kabupaten Merauke, Papua yang telah mendukung seluruh pelaksanaan penelitian ini.

\section{DAFTAR PUSTAKA}

Amalia, Ayu Diah (2015). Social Capital And Poverty. Jakarta, Jurnal Puslitbang Kemensos RI.

Coleman, J., (1990). Foundations of Social Theory. Cambridge Mass: Harvard University Press.

Fukuyama, F. (1992). The End of History and The Last Man. New York: Free Press
Hasbullah, J., (2006). Sosial Modal: Menuju Keunggulan Budaya Manusia Indonesia. Jakarta: MR-United Press.

James Midgley, (2005). "Pembangunan Sosial, Perspektif Pembangunan Dalam Kesejahteraan Sosial", Jakarta Ditperta Islam Depag RI.

Medco Foundation - Yasanto (2017), "Laporan Narasi, Survei Data Baseline Kampung Wapeko, Distrik Kurik, Kabupaten Merauke, Propinsi Papua", Jakarta, Laporan Internal

Medco Foundation - CSWS UNAIR (2016) "Resiko Sosial Pertanian Modern di Merauke", Jakarta, Laporan Internal.

Neuman, W. L. (2013). Metode Penelitian Sosial:Pendekatan Kualitatif dan Kuantitatif (7th Edition ed.). (B. Sarwaji, Penyunt., \& E. T. Sofia, Penerj.) Jakarta Barat, DKI Jakarta, Indonesia: PT. Indeks.

Lawang, Robert M.Z. (2005). Kapital Sosial Dalam Perspektif Sosiologi: Suatu Pengantar. Depok : FISIP UI Press.

Lawang, Robert M.Z. (2018). Social Poverty in two extreme cases in Manggarai - East Nusa Tenggara Province

Lewandowsky, Joseph D. (2008). On Social Poverty: Human Development and the Distribution of Social Capital. Journal of Poverty, Vol. $12 \quad$ (1) 2008. http://jpov.haworthpress.

UNESCO. (2002). Social Capital and Poverty Reduction. France: UNESCO.

Yamin, Sofyan; Dartanto, Teguh. (2016). Pengentasan Orang Miskin di Indonesia: Peran Modal Sosial yang Terlupakan; Jurnal Ekonomi dan Pembangunan Indonesia Vol. 17 No. 1 Juli 2016: 88-102

Zastrow, C. (2017). Introduction to Social Work and Social Welfare;12th Edition. Boston: Cengage Learning. 